\title{
Effects of High Pressure/High Temperature Processing on the Recovery and Characteristics of Porcine Placenta Hydrolysates
}

\author{
Mi-Yeon Lee ${ }^{1}$, Ye-Chul Choi ${ }^{1}$, Ji-Yeon Chun ${ }^{1}$, Sang-Gi Min, and Geun-Pyo Hong* \\ Department of Bio-Industrial Technologies, Konkuk University, Seoul 143-701, Korea \\ ${ }^{1}$ Department of Food Science and Biotechnology of Animal Resources, Konkuk University, Seoul 143-701, Korea
}

\begin{abstract}
This study was performed to investigate the effects of high pressure/high temperature (HPHT) treatment on the recovery efficiency and characteristics of porcine placenta hydrolysates. The placenta hydrolysates were characterized by solubility, free amino acid contents, gel electrophoresis, gel permeation chromatography (GPC) and amino acid composition. Placenta was treated at $37.5 \mathrm{MPa}$ of pressure combined with various temperatures $\left(150,170\right.$, and $\left.200^{\circ} \mathrm{C}\right)$ or various holding times $(0$, 30 , and $60 \mathrm{~min}$ at $170^{\circ} \mathrm{C}$ ). Insoluble raw placenta collagen was partially solubilized ( $>60 \%$ solubility) by the HPHT treatment. Free amino group content of placenta collagen was increased from $0.1 \mathrm{mM} / \mathrm{g}$ collagen to $>0.3 \mathrm{mM} / \mathrm{g}$ collagen after HPHT treatment, reflecting partial hydrolysis of collagen. The molecular weight $\left(M_{\mathrm{w}}\right)$ distribution showed evidence of collagen hydrolysis by shifting of $M_{\mathrm{w}}$ peaks toward low molecular weight when treated temperature or holding time was increased. Alanine (Ala), glycine (Gly), hydroxyproline (Hyp), and proline (Pro) contents increased after the HPHT treatments compared to a decrease in the others. In particular, the increase in Gly was obvious, followed by Hyp and Pro, reflecting that placenta hydrolysates were mainly composed of these amino acids. However, increasing temperature or holding time hardly affected the amino acid compositions. These results indicate that the HPHT treatment is advantageous to hydrolyze collagen derived from animal by-products.
\end{abstract}

Key words: high pressure, high temperature, subcritical water, placenta collagen, hydrolysis

\section{Introduction}

Collagen is a ubiquitous protein occurring in by-products such as tissues, bones, skins and organs of animals or marine organisms. Due to its low nutritional value and lack of essential amino acids, collagen has not been attracted much attention as an edible protein source. In contrast, collagen is an important source in medicine, pharmaceuticals, cosmetics as well as functional food industry because of its low biodegradability and less antigenicity (Kim et al., 2010; Zhang et al., 2006). Collagen is a high molecular weight $\left(M_{w}\right)$ protein $\left(M_{w}=300 \mathrm{kDa}\right)$ and is composed of three sub-chains of $\alpha_{1}, \alpha_{2}(\sim 100 \mathrm{kDa})$ and $\beta$ $(\sim 200 \mathrm{kDa})$ associated through a triple-helix structure (Zhang et al., 2006). Although collagen is classified into several types based on chain composition, the primary structure of collagen is normally characterized by the pres-

*Corresponding author: Geun-Pyo Hong, Department of BioIndustrial Technologies, Konkuk University, Seoul 143-701, Korea. Tel: 82-2-450-3674, Fax: 82-2-455-1044, E-mail: genpro (a)konkuk.ac.kr ence of an uninterrupted glycine-X-Y repetition in which $\mathrm{X}$ and $\mathrm{Y}$ are mainly composed of Pro and Hyp (Miller, 1988).

Low $M_{w}$ peptides derived from various proteins have been extensively investigated due to their physiological functions including anti-osteoarthritis, anti-osteoporosis, anti-oxidation and anti-hypertension properties (Denis et al., 2008). Commercial collagen hydrolysates are obtained by treatment with proteases such as trypsin, pepsin, chymotrypsin, alcalase, collagenase, and papain (GómezGuillén et al, 2011). Insoluble collagen must be converted to a soluble gelatin by mild thermal treatment prior to enzymatic hydrolysis, thereafter being partially hydrolyzed by acidic or alkaline treatment (Denis et al., 2008). However, this procedure requires too long processing time to achieve low $M_{w}$ collagen peptides.

Hot pressurized water (namely subcritical water) treatment has been studied as a novel protein hydrolysis technology. The critical point of water is $374^{\circ} \mathrm{C}$ and $22 \mathrm{MPa}$ at which the water ionization constant increases, hence, water ionizes readily to hydrogen and hydroxide ions (Watchararuji et al., 2008). Hydrogen ions disrupt peptide 
bonding thereby resulting in hydrolysis of peptides (Brunner, 2009). Information about the effects of subcritical water on the hydrolysis of soybean and rice bran protein is available (Sunphorka et al., 2012; Watchararuji et al., 2008). However, there was no study about collagen hydrolysis using subcritical water. Therefore, we investigated the effects of various high pressure/high temperature (HPHT) processing conditions on the recovery efficiency and the characteristics of porcine placenta hydrolysates.

\section{Materials and Methods}

\section{Materials}

Frozen porcine placenta was kindly provided by Samwoo Husbandry (Korea). The frozen placenta was thawed at $4^{\circ} \mathrm{C}$ overnight and washed in water several times to remove residual blood. All visible fat was trimmed off and the placenta was cut into $5 \mathrm{~cm}$ lengths. The moisture content of the placenta was estimated according to AOAC (1990). Crude protein of the porcine placenta was determined by Kjeldahl $(\% N \times 6.25)$. Approximately $100 \mathrm{~g}$ of placenta was vacuum-packaged and frozen at $-50^{\circ} \mathrm{C}$ prior to use (within $2 \mathrm{wk}$ ). All chemicals used in this study were analytical grade and purchased from Sigma-Aldrich Corp. (USA).

\section{Treatments}

A lab-scale high pressure system equipped with an ohmic heater was used to extract and hydrolyze the placenta. In brief, the system was composed of a S-40 pressure generator (Seowon Compressor Co., Korea), a HSF-300 pressure intensifier (Haskel International Inc., USA), a pressure vessel with working volume of $1 \mathrm{~L}$, and an ohmic heater connected with a SDU-990 temperature controller (TC
Sensor Manufacturing Ltd., Korea) as depicted in Fig. 1. Water was used as the pressure-transmitting medium. Vacuum-packaged frozen placenta was thawed overnight and blended using a HR-2084 food processor (Philips Electronics, Korea). Aliquots $30 \mathrm{~g}$ of placenta homogenates were filled into a polyimide film and sealed with precursor using a MH-7 heating press (Masada Seisakusho Co. Ltd., Japan). Samples were divided into two groups for two different experiments to evaluate the temperature and holding time effects. Samples in the first group were inserted into the vessel and heated from $20^{\circ} \mathrm{C}$ to the target temperature $\left(150,170\right.$, or $\left.200^{\circ} \mathrm{C}\right)$ under $37.5 \mathrm{MPa}$ of pressure. When the inner vessel temperature reached the target, the vessel was cooled down to $40^{\circ} \mathrm{C}$ using ice. The remaining samples were heated under $37.5 \mathrm{MPa}$ of pressure to evaluate the effects of holding time. When vessel temperature was $170^{\circ} \mathrm{C}$, the samples were held for 0,30 , and $60 \mathrm{~min}$ under the pressure/temperature-controlled conditions and cooled down to $40^{\circ} \mathrm{C}$ using ice. After cooling, the samples were removed from the vessel and analyzed without further storage. A non-treated sample was used as a control.

\section{Gel electrophoresis}

After treatment, samples (control and treatment at $170^{\circ} \mathrm{C}$ for $30 \mathrm{~min}$ ) were transferred to test tube and vigorously vortexed. Aliquots $100 \mu \mathrm{L}$ of sample were diluted with $400 \mu \mathrm{L}$ of $8 \mathrm{M}$ urea (final protein concentration of $4 \mathrm{mg}$ / $\mathrm{mL}$ ). Peptide profiles of the sample were determined by sodium dodecyl sulfate-polyacrylamide gel electrophoresis (SDS-PAGE) using EzWay ${ }^{\mathrm{TM}}$ PAG 6\% acrylamide gels (KOMA Biotech Inc., Korea) based on the method of Laemmli (1970). The sample was mixed with one part KTG 020 sample buffer (KOMA Biotech Inc., Korea), consist-

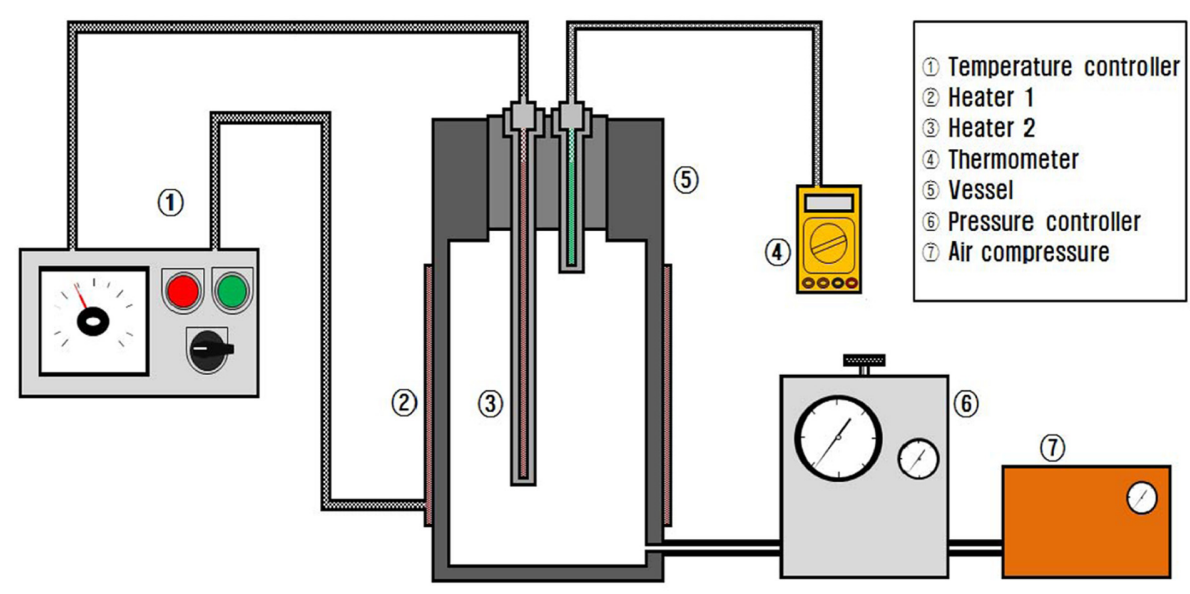

Fig. 1. Schematic diagram of the high pressure/high temperature processing apparatus. 
ing of $10 \%$ glycerol, $2 \%$ SDS, $0.003 \%$ bromophenol blue, $5 \% \beta$-mercaptoethanol and $63 \mathrm{mM}$ Tris, $\mathrm{pH}$ 6.8). The sample was boiled for $2 \mathrm{~min}$ and $20 \mu \mathrm{L}$ of sample mixture was loaded into the gel wells. Peptide separation was performed at a constant voltage of $140 \mathrm{~V}(\sim 1 \mathrm{~h})$.

\section{Solubility}

All treatments were centrifuged at $1,000 \mathrm{~g}$ for $15 \mathrm{~min}$, and the supernatant was collected. The protein content of the supernatant was determined by the method of Kjeldahl $(\% N \times 6.25)$ and solubility was expressed as percent protein recovery in the supernatant over the initial protein content in the sample.

\section{Free amino group content}

Free amino group content was determined by the method of Benjakul and Morrissey (1997). The sample supernatant $(125 \mu \mathrm{L})$ was mixed with $2 \mathrm{~mL} 0.2125 \mathrm{M}$ sodium phosphate buffer (pH 8.2), and $1 \mathrm{~mL} \mathrm{0.01 \%} \mathrm{2,4,6-trinitroben-}$ zenesulfonic acid was added into the sample mixture. The mixture was thermal-treated at $50^{\circ} \mathrm{C}$ for $30 \mathrm{~min}$, and $2 \mathrm{~mL}$ of $0.1 \mathrm{M}$ sodium sulfite was added to the sample to terminate the reaction. The mixture was cooled at ambient temperature for $15 \mathrm{~min}$ and absorbance was measured at 420 $\mathrm{nm}$. The free amino group content was expressed in terms of L-leucine (Nagarajan et al., 2012).

\section{Molecular weight distribution}

The molecular weight $\left(M_{w}\right)$ distribution of collagen peptides in the supernatant was determined by the method of Gu et al. (2011) with minor modifications. Gel permeation chromatography was performed using a YL 9100 high performance liquid chromatography (HPLC) system (Younglin Instrument Co. Ltd., Korea) equipped with three Ultrahydrogel $^{\text {TM }} 120$ columns $(7.8 \times 3,000 \mathrm{~mm}$, Waters, USA). The mobile phase was distilled/deionized water at a flow rate of $1 \mathrm{~mL} / \mathrm{min}$, and the $M_{w}$ distributions of the collagen peptides were monitored using a YL 9100 refractive index detector (YL Instrument Co. Ltd., Korea) at $40^{\circ} \mathrm{C}$. A molecular weight standards kit $(0.68-1,670 \mathrm{kDa}$, Polymer standards service, Germany) was used as standards.

\section{Amino acid composition}

Amino acid composition of the sample supernatant was determined using an Agilent HPLC 1200 system (Agilent Technologies Inc., USA) equipped with two detectors (a fluorescence detector and a UV detector) and a $\mathrm{C}_{18}$ column $(4.6 \times 150 \mathrm{~mm}, 5 \mu \mathrm{m}$ in diameter). The supernatant containing $3 \mathrm{mg}$ of total protein was added to $30 \mathrm{~mL}$ of $6 \mathrm{M}$
$\mathrm{HCl}$ and hydrolyzed at $130^{\circ} \mathrm{C}$ for $24 \mathrm{~h}$. After hydrolysis, the sample was diluted with distilled/deionized water up to total volume of $100 \mathrm{~mL}$, and then filtered using a DISMIC-13CP $0.45 \mu \mathrm{m}$ syringe filter (Advantec Co., Japan). Two mobile phases were applied, i.e., one was $20 \mathrm{mM}$ sodium phosphate buffer ( $\mathrm{pH} 7.8$ ) and the other was $45 \%$ $(\mathrm{v} / \mathrm{v})$ acetonitrile $/ 45 \%(\mathrm{v} / \mathrm{v})$ methanol solution. The samples were monitored at an emission wavelength of 450 $\mathrm{nm}$ and an excitation wavelength of $340 \mathrm{~nm}$ for the $o$ phthalaldehyde derivatives, and an emission wavelength of $305 \mathrm{~nm}$ and an excitation wavelength of $266 \mathrm{~nm}$ for the 9-fluorenylmethyl chloroformate derivatives at $40^{\circ} \mathrm{C}$ in the case of fluorescence detecting and an absorbance at 338 $\mathrm{nm}$ at $40^{\circ} \mathrm{C}$ in the case of UV detecting. An Agilent 50613330 (Agilent Technologies Inc., USA) was used as the standard.

\section{Statistical analysis}

A completely randomized design was adopted. Data collected from the triplicate determinations of each sample repeated twice are presented as mean \pm standard deviation. Analysis of variance was performed, and the mean differences were identified by Duncan's multiple range test using a SAS statistical software ver. 9.1 (SAS Institute, USA).

\section{Results and Discussion}

\section{Solubility}

The ground placenta was insoluble in water and exhibited $2.9 \%$ protein recovery in the supernatant (Fig. 2). A small portion of soluble protein would account for the minor contaminant possibly originating from blood. HPHT processing increased the solubility of the porcine placenta. The solubility of placenta was $58 \%$ when HPHT processing was applied at $150^{\circ} \mathrm{C}$ (Fig. 2A). More protein (71\%) was recovered in the supernatant by increasing processing temperature $\left(170^{\circ} \mathrm{C}\right)(p<0.05)$. Insoluble collagen is converted into soluble gelatin in water following mild thermal treatment (Montero and Gómez-Guillén, 2000). In this study, the applied temperatures $\left(150-170^{\circ} \mathrm{C}\right)$ were high enough for placenta collagen to convert to gelatin, which could increase solubility of the samples in the supernatant. In addition, ionization of water under the HPHT conditions caused a decrease in water $\mathrm{pH}$, hence, placenta collagen would be partially hydrolyzed to soluble peptides (Zhu et al., 2011). In contrast, the HPHT processing at $200^{\circ} \mathrm{C}$ caused a drastic decrease in solubility $(55 \%)$ of placenta $(p<0.05)$.

A parabolic change in placental solubility by the effect 

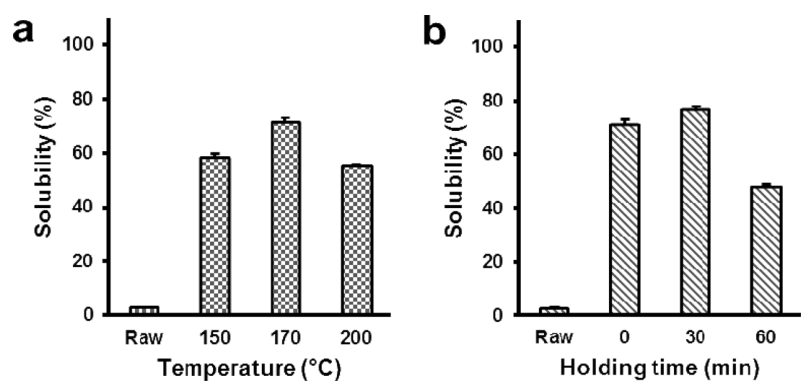

Fig. 2. Solubility profiles of raw (control) and high pressure/ high temperature (HPHT) treated porcine placenta (A) at various temperatures for $0 \mathrm{~min}$ and $(\mathrm{B})$ at $170^{\circ} \mathrm{C}$ for various holding times. All HPHT treated placenta suspensions were treated at $37.5 \mathrm{MPa}$ of pressure. Vertical bars indicate standard deviations.

temperature was observed when the placenta was subjected to HPHT processing at $170^{\circ} \mathrm{C}$ for various holding times (Fig. 2B). The solubility of placenta was increased to $77 \%$ until $30 \mathrm{~min}$ of treatment at $170^{\circ} \mathrm{C}$. Thereafter solubility was decreased down to $48 \%(p<0.05)$. These phenomena could be explained by decomposition of collagen peptides. Sunphorka et al. (2012) indicated that protein content of subcritical-processed rice bran decreases with increasing holding time, whereas amino acid content increased. Similarly, decomposition of amino acids occurs following subcritical $\left(190-260^{\circ} \mathrm{C}\right)$ water treatment (Amashukeli et al., 2007; Dunn and Brophy, 1932). Consequently, the decomposition of peptides and amino acids would account for a decrease in solubility of the porcine placenta suspension.

\section{Free amino group content}

It was unclear how much placenta was hydrolyzed by the HPHT processing, because the amounts of soluble gelatin and collagen hydrolysates could not be quantified. Protein decomposition was determined in terms of free amino group content to evaluate the amount of hydrolyzed placenta (Nagarajan et al., 2012) and the results are depicted in Fig. 3. The free amino group content of raw placenta was $0.10 \mathrm{mM} / \mathrm{g}$ and increased up to $0.26 \mathrm{mM} / \mathrm{g}$ after HPHT treatment at $150^{\circ} \mathrm{C}(p<0.05)$ (Fig. 3A). The free amino group content was further increased with increasing temperature and was $0.31 \mathrm{mM} / \mathrm{g}$ at $170^{\circ} \mathrm{C}(p<$ 0.05 ), confirming hydrolysis of placenta collagen. No difference in free amino group content occurred between the $170^{\circ} \mathrm{C}$ and $200^{\circ} \mathrm{C}$ treatments. The results indicate that HPHT processing at $170^{\circ} \mathrm{C}$ was the best condition from an energy efficiency perspective. Placenta hydrolysis may have occurred at $>170^{\circ} \mathrm{C}$, whereas decomposition of free amino acids would also occur (Amashukeli et al., 2007),
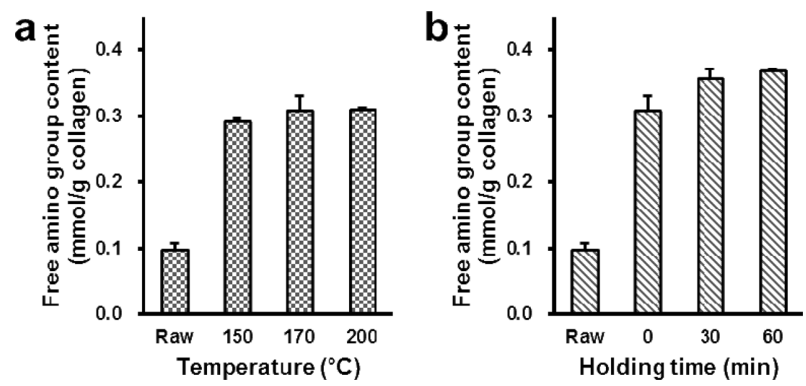

Fig. 3. Free amino group contents of raw (control) and high pressure/high temperature (HPHT) treated porcine placenta (A) at various temperatures for $0 \mathrm{~min}$ and $(B)$ at $170^{\circ} \mathrm{C}$ for various holding time. All HPHT treated placenta suspensions were treated at $37.5 \mathrm{MPa}$ of pressure. Vertical bars indicate standard deviations.

resulting in no significant increase in free amino group content of porcine placenta.

Increasing the holding time at $170^{\circ} \mathrm{C}$ was also attributed to higher free amino group content (Fig. 3B). The free amino group content increased from 0.31 to $0.36 \mathrm{mM} / \mathrm{g}$ by increasing the holding time from 0 to $30 \mathrm{~min}(p<0.05)$. Alternately, further increasing holding time $(60 \mathrm{~min})$ resulted in a gradual increase in free amino group content $(0.37 \mathrm{mM} / \mathrm{g})$ compared to that at $30 \mathrm{~min}$. Nevertheless the impact of the 60 min treatment was not significant compared to that at $30 \mathrm{~min}$. Higher pressure level (100 MPa, $170^{\circ} \mathrm{C}, 30 \mathrm{~min}$ ) was also compared with the corresponding counterpart of $37.5 \mathrm{MPa}$ treatment $\left(170^{\circ} \mathrm{C}, 30 \mathrm{~min}\right)$, but no difference in protein recovery or free amino group content was observed (data not shown). These results indicate that the main factor affecting placenta hydrolysis during HPHT processing was not pressure but temperature. Based on these results, the optimum condition of HPHT processing for placenta hydrolysis was $170^{\circ} \mathrm{C}$ for $30 \mathrm{~min}$, where product yield was maximum.

\section{Gel electrophoresis}

Porcine placenta peptides exhibited four major bands near 200 and $100 \mathrm{kDa}$ (Fig. 4). The former indicates $\alpha$ chains (namely $\alpha 1$ and $\alpha 2$ ) which have $M_{w}$ of $116 \mathrm{kDa}$ and the latter were $\beta$-chains $(205 \mathrm{kDa})$ as revealed in other studies (Ahmad et al., 2010; Klomklao et al., 2006; Liu et al., 2012). These results indicate that the composition of protein in porcine placenta was mainly collagen. There was no difference in SDS-PAGE profiles between reducing and non-reducing conditions reflecting no disulfide bond in placenta peptides. Most bands lost their intensity following the HPHT processing $\left(170^{\circ} \mathrm{C}\right.$ for $\left.30 \mathrm{~min}\right)$ and the bands were shifted to low $M_{w}$ ranges $(<55 \mathrm{kDa})$. These changes in collagen band profiles were in agreement with 


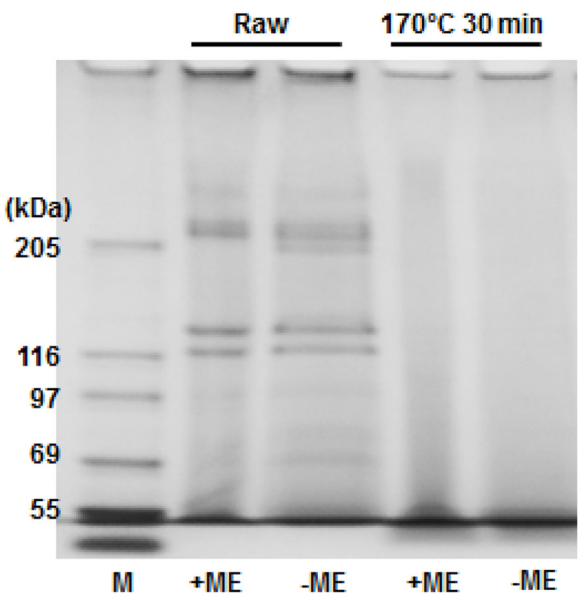

Fig. 4. SDS-PAGE profiles of non-reduced (-ME) and reduced (+ME) raw (control) and high pressure/high temperature (HPHT) treated porcine placenta. The HPHT treatment was conducted at $170^{\circ} \mathrm{C}$ for 30 min under 37.5 MPa. Lane M indicates molecular weight standard.

Zhang et al. (2006) who reported that gelatin and/or collagen hydrolysate exhibit a broad distribution with lower $M_{w}$ than collagen. In contrast to enzymatic hydrolysis, which has several steps in hydrolysis from long chains to short chains (or amino acid), thermal hydrolysis of collagen occurred at relatively high temperature $\left(>150^{\circ} \mathrm{C}\right)$, hence SDS-PAGE profiles of HPHT treatments in the present study exhibited same results regardless of temperature and holding time (data not shown).

\section{Molecular weight distribution}

Due to the insoluble properties of raw placenta, no $M_{w}$ peak was observed in the control supernatant (Fig. 5). The HPHT treatment at $150^{\circ} \mathrm{C}$ exhibited two distinctive peak groups out of the range of the $M_{w}$ standards (Fig. 5A). The first group consisted of four high $M_{w}$ peaks ( $\left.>20.1 \mathrm{kDa}\right)$ and the second group was two low $M_{w}$ peaks $(<106 \mathrm{Da})$. The former would be solubilized gelatin and/or partially hydrolyzed high $M_{w}$ peptides, and the latter possibly indicated small units of peptide hydrolysates. Increasing temperature shifted the high $M_{w}$ peaks toward the lower $M_{w}$ region. Moreover, the highest $M_{w}$ peak mostly disappeared at $200^{\circ} \mathrm{C}$, whereas new peaks were generated in the average $M_{w}$ range of 1,400-4,270 $\mathrm{Da}$ and $424 \mathrm{Da}$, indicating that hydrolysis of placenta progressed with increasing temperature.

Similar results were also obtained when the placenta was treated by HPHT processing at constant temperature (170 ${ }^{\circ} \mathrm{C}$ ) and increasing holding time (Fig. 5B). Movements of peaks toward the low $M_{w}$ region was not considerable between the 0 and $30 \mathrm{~min}$ treatments, whereas the $60 \mathrm{~min}$

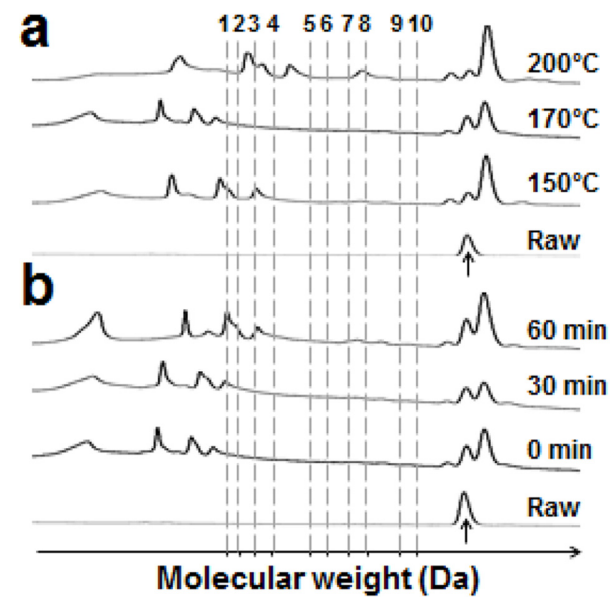

Fig. 5. Relative molecular weight distributions of raw (control) and high pressure/high temperature (HPHT) treated porcine placenta (A) at various temperatures for $0 \mathrm{~min}$ and (B) at $170^{\circ} \mathrm{C}$ for various holding time. All HPHT treated placenta suspensions were treated at $37.5 \mathrm{MPa}$ of pressure. Molecular weights presented as Arabic numbers are (1) 20,100 Da, (2) 12,600 Da, (3) 6,950 Da, (4) 4,270 Da, (5) 1,400 Da, (6) 985 Da, (7) 626 Da, (8) 434 Da, (9) 222 Da and (10) 106 Da. Upper arrows indicate system peaks.

HPHT treatment resulted in relatively low $M_{w}$ peaks and a new peak. Nevertheless, the overall peak $M_{w}$ from the HPHT treatment at $170^{\circ} \mathrm{C}$ for $60 \mathrm{~min}$ was higher than those treated at $200^{\circ} \mathrm{C}$ for $0 \mathrm{~min}$. The results demonstrate that HPHT processing has a potential advantage to produce small peptides derived from animal by-products. Although, there is no comparative literature, HPHT processing enabled to produce collagen peptides without chemical treatment within $1 \mathrm{~h}$.

\section{Amino acid profiles}

The amino acid compositions of the HPHT treated placenta were determined (Fig. 6). Raw placenta exhibited various amino acid compositions. In particular, Asp, Glu, and Gly exhibited $>10 \%$ of total amino acid profiles. These amino acid profiles were similar to those obtained by $\mathrm{Gu}$ et al. (2011). Nalinamon et al. (2011) reported that the major amino acids of type I collagen extracted from ornate threadfin bream were Ala (13.4\%), Gly (32.1\%), and Pro (10.4\%). Different compositions of collagen are due to different sources (animals versus marine organisms) and different experimental conditions (supernatant versus whole collagen). It is reported that placental membranes contain type I and VII collagens compared to type IV and VI collagens in placental villi (Miller, 1988). Although collagen type is classified by sub-chain composition, each sub-chain exhibits similar amino acid composition (Nimni and Hark- 

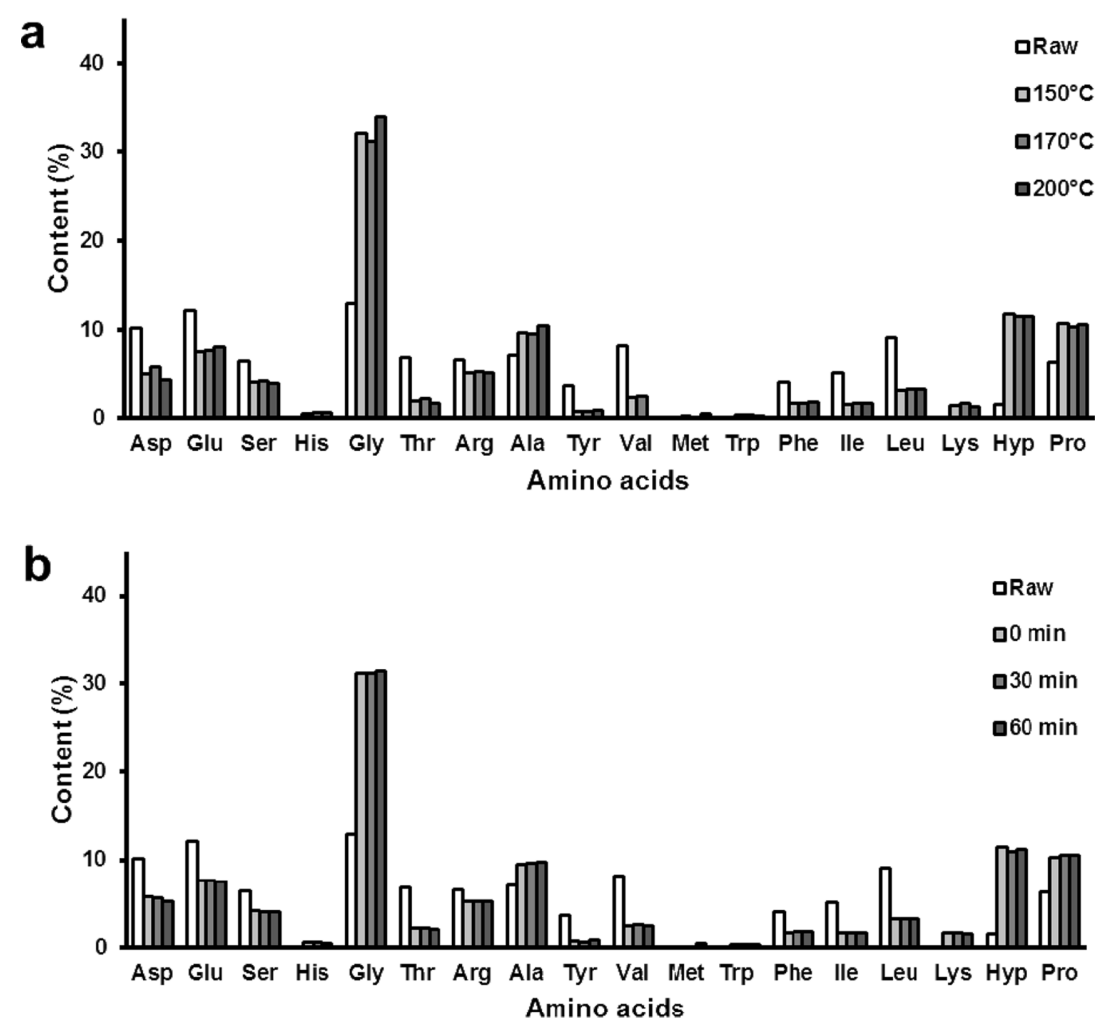

Fig. 6. Amino acid compositions of raw (control) and high pressure/high temperature (HPHT) treated porcine placenta (A) at various temperatures for $0 \mathrm{~min}$ and $(\mathrm{B})$ at $170^{\circ} \mathrm{C}$ for various holding times. All HPHT treated placenta suspensions were treated at 37.5 MPa of pressure.

ness, 1988). It should be noted that the amino acids of raw placenta in this study were based on the supernatant (solubilized proteins). Regardless of treatment conditions, the amino acid contents of most placenta supernatants decreased greatly after HPHT treatment with the exception of Gly, Ala, Hyp and Pro which increases in content over the total amino acid compositions $(p<0.05)$. These patterns exhibited typical amino acid profiles of collagen (Nalinamon et al., 2011; Nimni and Harkness, 1988). However, no differences in amino acid contents were observed among treatments, indicating that the collagen extraction and hydrolysis could be achieved by HPHT processing.

\section{Conclusion}

This study applied HPHT processing to extract and hydrolyze porcine placenta collagen. Among the physical factors, increasing temperature produced low $M_{w}$ collagen peptides rather than holding time. Based on the results, HPHT processing at $170^{\circ} \mathrm{C}$ for $30 \mathrm{~min}$ was favorable to produce low Mw collagen peptide. Although the main mechanisms involved in collagen hydrolysis under high pressure and high temperature domains are still obscure, HPHT processing exhibited the best way to achieve value-added col- lagen hydrolysates from less valuable animal wastes or by-products.

\section{Acknowledgement}

This study was supported by a grant from Korea Institute of Planning and Evaluation for Technology in Food, Agriculture, Forestry, and Fisheries (iPET Project No. 311029-3).

\section{References}

1. Ahmad, M., Benjakul, S., and Nalinanon, S. (2010) Compositional and physicochemical characteristics of acid solubilized collagen extracted from the skin of unicorn leatherjacket (Aluterus monoceros). Food Hydrocolloid. 24, 588-594.

2. Amashukeli, X., Pelletier, C. C., Kirby, J. P., and Grunthaner, F. J. (2007) Subcritical water extraction of amino acids from Atacama Desert soils. J. Geophys. Res. 112, G04S16.

3. AOAC. (1990) Official methods of analysis. 15th ed, Association of Official Analytical Chemists, Washington, DC.

4. Benjakul, S. and Morrissey, M. T. (1997) Protein hydrolysates from pacific whiting solid wastes. J. Agric. Food Chem. 45, 3423-3430.

5. Brunner, G. (2009) Near critical and supercritical water. Part I. Hydrolytic and hydrothermal processes. J. Supercritical Fluid. 47, 373-381. 
6. Denis, A., Brambati, N., Dessauvages, B., Guedj, S., Ridoux, C., Meffre, N., and Autier, C. (2008) Molecular weight determination of hydrolyzed collagens. Food Hydrocolloid. 22, 989-994.

7. Dunn, M. S. and Brophy, T. W. (1932) Decomposition points of the amino acids. J. Biol. Chem. 99, 221-229.

8. Gómez-Guillén, M. C., Giménez, B., López-Caballero, M. E., and Montero, M. P. (2011) Functional and bioactive properties of collagen and gelatin from alternative sources: A review. Food Hydrocolloid. 25, 1813-1827.

9. Gu, R. Z., Li, C. Y., Liu, W. Y., Yi, W. X., and Cai, M. Y. (2011) Angiotensin I-converting enzyme inhibitory activity of low-molecular-weight peptides from Atlantic salmon (Salmo salar L.) skin. Food Res. Int. 44, 1536-1540.

10.Kim, B. Y., Kim, T., Kang, W. Y., Hyun, B., Cheon, H. Y., and Kim, D. (2010) Functional cosmetic effect of porcine placenta. Korean Chem. Eng. Res. 48, 327-331.

11. Klomklao, S., Benjakul, S., Visessanguan, W., Kishimura, H., and Simpson, B. K. (2006) Proteolytic degradation of sardine (Sardinella gibbosa) proteins by trypsin from skipjack tuna (Katsuwonus pelamis) spleen. Food Chem. 98, 14-22.

12. Laemmli, U. K. (1970) Cleavage of structural proteins during assembly of head of bacteriophage T4. Nature 227, 680-685.

13. Liu, D., Liang, L., Regenstein, J. M., and Zhou, P. (2012) Extraction and characterization of pepsin-solubilised collagen from fins, scales, skins, bones and swim bladders of bighead carp (Hypophthalmichthys nobilis). Food Chem. 133, 14411448.

14. Miller, E. J. (1988) Collagen types: Structure, distribution, and functions. In: Collagen. Nimni, M. E. (ed) Boca Raton, CRC Press, Boca Raton, 1, pp. 139-156.
15. Montero, P. and Gómez-Guillén, M. C. (2000) Extracting conditions for megrim (Lepidorhombus boscii) skin collagen affect functional properties of the resulting gelatin. J. Food Sci. 65, 434-438.

16. Nagarajan, M., Benjakul, S., Prodpran, T., Songtipya, P., and Kishimura, H. (2012) Characteristics and functional properties of gelatin from splendid squid (Loligo formosana) skin as affected by extraction temperatures. Food Hydrocolloid. 29, 389-397.

17. Nalinanon, S., Benjakul, S., Kishimura, H., and Osako, K. (2011) Type I collagen from the skin of ornate threadfin bream (Nemipterus hexodon): Characteristics and effect of pepsin hydrolysis. Food Chem. 125, 500-507.

18. Nimni, M. E. and Harkness, R. D. (1988) Molecular structure and functions of collagen. In: Collagen. Nimni, M. E. Boca Raton, CRC Press, 1, 1-77.

19. Sunphorka, S., Chavasiri, W., Oshima, Y., and Ngamprasertsith, S. (2012) Kinetic studies on rice bran protein hydrolysis in subcritical water. J. Supercritical Fluid. 65, 54-60.

20. Watchararuji, K., Goto, M., Sasaki, M., and Shotiprunk, A. (2008) Value-added subcritical water hydrolysate from rice bran and soybean meal. Bioresour. Technol. 99, 6207-6213.

21. Zhang, Z., Li, G., and Shi, B. (2006) Physicochemical properties of collagen, gelatin and collagen hydrolysate derived from bovine limed split wastes. J. Society Leather Technol. Chem. 90, 23-28.

22. Zhu, G., Zhu, X., Fan, Q., and Wan, X. (2011) Recovery of biomass wastes by hydrolysis in sub-critical water. Resour. Conserv. Recy. 55, 409-416.

(Received 2013.5.8/Revised 2013.7.10/Accepted 2013.7.22) 